\title{
The Expression of Self-compatibility in Almond May Not Only Be Due to the Presence of the $S_{f}$ Allele
}

\author{
Ossama Kodad and Rafel Socias i Company ${ }^{1}$ \\ Unidad de Fruticultura, Centro de Investigación y Tecnología Agroalimentaria de Aragón (CITA), \\ Av. Montañana 930, 50059, Zaragoza, Spain
}

Ana Sánchez
Instituto de Tecnologia Química e Biológica (ITQB), Quinta do Marquês, 2784-505 Oeiras, Portugal

M. Margarida Oliveira

Instituto de Tecnologia Química e Biológica (ITQB), Instituto de Biologia Experimental e Tecnológica (IBET), Quinta do Marquês, 2784-505 Oeiras, Portugal, and Universidade de Lisboa, Faculdade de Ciencias, Dep. de Biologia Vegetal, Campo Grande, 1749-016 Lisbon, Portugal

\begin{abstract}
AdDitional Index words. Prunus amygdalus, PCR analysis, sequencing, pollination
Abstract. The pistil ( $S$-RNase) and the pollen $\left[S\right.$-haplotype-specific F-box protein (SFB)] components of the $S_{f}$ allele, presumably conferring self-compatibility in almond \{Prunus amygdalus Batsch [syn. P. dulcis (Mill.) D.A. Webb]\}, were identified and sequenced in 'Ponç', a local Spanish almond cultivar, confirming their identity with the published sequences of these components. Despite the presence of the $S_{f}$ allele, the 'Ponç' phenotype was self-incompatible as confirmed by different pollination tests, including self pollen tube growth, fruit set after self-pollination, and fruit set in bagged branches. However, the pistil and the pollen of 'Ponc' were fully viable when pollinated by a crosscompatible pollen or used on a cross-compatible pistil. The fact that 'Ponç' presents two different $S$-proteins with RNase activity may indicate an active function of its $S_{f}$-RNase, whereas in the self-compatible almond cultivars thus far studied, the $S_{f}$-RNase has been inactive. This activation indicates that the presence of the $S_{f}$ allele may not be the exclusive source of self-compatibility in almond, and other factors may also be involved in the expression of almond self-compatibility.
\end{abstract}

Self-incompatibility (SI) is the ability of a fertile hermaphrodite flowering plant to prevent self-fertilization by discriminating between self and nonself pollen. In almond, as well as in other Prunus L. species, the SI system is of the gametophytic type (Socias i Company et al., 1976) and is controlled by a single $S$ locus with multiple alleles (Crane and Lawrence, 1929). To ensure that flowers may be efficiently pollinated to reach an economically acceptable fruit set (Kester and Griggs, 1959), insect-dependent cross-pollination of intercompatible and simultaneously blooming cultivars is required. As an alternative to SI cultivars, self-compatible (SC) ones may be used to expand monovarietal orchards (Socias i Company, 1990).

To breed SC cultivars, it is important to understand the molecular mechanisms underlying this behavior. The $S$ locus produces in the pistil a basic glycoprotein with ribonuclease $(S$ RNase) activity (McClure et al., 1989). This protein is taken up by the growing pollen tubes, causing their subsequent arrest in the style and thus preventing self-fertilization by its own pollen (Kao and Tsukamato, 2004). The expression of SC in almond is attributed to the presence of the $S_{f}$ allele, whose expression is

\footnotetext{
Received for publication 17 Oct. 2008. Accepted for publication 22 Dec. 2008. This work was supported by the Spanish Interministerial Commission for Science and Technology (CICYT; grant no. AGL2007-65853-C02-02) and by research line L38 of the Instituto de Tecnologia Química e Biológica (Portugal). O. Kodad gratefully acknowledges a scholarship from the Spanish National Institute for Agricultural and Food Research and Technology (INIA) and from the Consolidated Research Group A12 of Aragón.

We thank O. Frontera and J. Búbal for their technical assistance.

${ }^{1}$ Corresponding author. E-mail: rsocias@aragon.es.
}

dominant over the other alleles of the $S$ series (Socias i Company, 1984). Bošković and Tobutt (1996) reported that in cherry (Prunus avium L.), the $S$ alleles code for stylar ribonucleases that can be detected by electrophoretic separation of stylar proteins and subsequent staining for activity. In almond, Bošković et al. $(1999,2003)$ applied the analysis of stylar $S$-RNases by nonequilibrium $\mathrm{pH}$ gradient electrofocusing (NePHGE) to detect SC seedlings in almond progenies from crosses in which one parent was SC. In these analyses, SC cultivars only showed one band with RNase activity. Additional studies carried out at the genetic level allowed the partial sequence of the $S_{f}$ allele gene associated with $S$-RNase of SC in almond to be obtained (Channuntapipat et al., 2001; Ma and Oliveira, 2001).

The origin and the mechanism of almond SC are still unknown. Two hypotheses have been put forward to explain how SC appeared. The first hypothesis suggests a natural mutation in the SI system (Crossa-Raynaud and Grasselly, 1985), and the second suggests a gene transfer through spontaneous interspecific hybridization between Prunus amygdalus and P. webbii (Vierh.) Spach (Socias i Company, 2004). Independent of its origin, it is accepted that the loss of activity of an $S$-RNase in the style is the possible reason for SC in almond (Bošković et al., 1999). Supporting the previous suggestions from Bošković et al. (1999), Hanada et al. (2009) have reported that the possible origin of SC in almond may be due to the lack of or to the very low level of the transcription of the $S$-RNase in the pistil. However, Bošković et al. (2007) have suggested another possible origin for 'Tuono' $\mathrm{SC}$ - a mutation in the $\mathrm{C} 2$ region from histidine to arginine. Both hypotheses 
could explain the absence of RNase activity repeatedly observed in SC almond genotypes (Alonso and Socias i Company 2005; Bošković et al., 1999).

In other studies, Ushijima et al. (2003) sequenced, for the first time, the pollen $S$ haplotype termed F-Box (SFB), finding that this could be a good candidate for the pollen $S$ product because it was confirmed to be specifically expressed in the pollen tube and to be physically linked to the $S$-RNase gene (Entani et al., 2003, Ikeda et al., 2005). SFB features such as pollen-specific expression, tight linkage with the $S$-RNase gene, a high level of allelic polymorphism, and the presence of regions under positive selection are consistent with this being the pollen determinant in Prunus (Entani et al., 2003; Ikeda et al., 2004, 2005; Yamane et al., 2003). Hanada et al. (2009) have sequenced the $\mathrm{SFB}_{\mathrm{f}}$ in $\mathrm{SC}$ 'Lauranne' and found the same sequence as did Bošković et al. (2007) in SC 'Tuono' and in SI 'Cinquanta Vignali' and 'Fra Giulio Grande'.

Recently, Kodad et al. (2008) identified the $S$ genotype of 39 cultivars in the almond germplasm bank of Zaragoza, Spain, using the PCR approach, combining different primers. Several Spanish local cultivars from the island of Majorca, including Ponç, were found to posses the consensus $S_{f}$ allele as sequenced by Channuntapipat et al. (2001), considered to confer the SC trait in almond. This cultivar presents high productivity, good nut quality, medium blooming time, and good behavior under drought conditions (Rubí, 1980). The confirmation of SC in 'Ponç' would also open new horizons in almond breeding programs as an alternative source of SC other than 'Tuono' and closely related cultivars from the Italian region of Puglia (Socias $i$ Company, 2002). This alternative would avoid the problems related to inbreeding in the expression and transmission of SC in almond, which presumably results from lethal and deleterious genes that also affect some horticultural traits, including vigor, bud density, and plant size (Alonso and Socias i Company, 2007).

The aim of this work was to confirm the molecular identity of the $S_{f}$-RNase and $\mathrm{SFB}_{\mathrm{f}}$ of 'Ponç' by genomic DNA sequencing and by comparison with the $S$ genotype of other SC cultivars. This study was complemented by assessing pollen tube growth and fruit set, after controlled artificial selfpollination and bagging branches at bloom, as an indicator of phenotypic expression of SC/SI.

\section{Materials and Methods}

Plant material. Nine almond genotypes were studied. Four of these, 'Ponç', 'Desmayo Largueta' $\left[S_{1} S_{10}\right.$ (Ortega et al., 2006)], 'Marcona' $\left[S_{11} S_{12}\right.$ (Bošković et al., 1999)], and 'Bertina' $\left[S_{6} S_{11}\right.$ (Bošković et al., 1999)] are local Spanish cultivars, and three, 'Soleta' $\left(S_{f} S_{23}\right)$, 'Cambra' $\left(S_{f} S_{3}\right)$, and selection G-2-22 $\left[S_{f} S_{6}\right.$ (Kodad and Socias i Company, 2008; Kodad et al., 2008)], are releases from the Centro de Investigación y Tecnología Agroalimentaria de Aragón (CITA) breeding program. 'Tuono' $\left[S_{f} S_{1}\right.$ (Crossa-Raynaud and Grasselly, 1985)] is the most used SC cultivar in breeding programs, and 'Ferragnès' [ $S_{1} S_{3}$ (Crossa-Raynaud and Grasselly, 1985)] is a release from the Institut National de la Recherche Agronomique, France (INRA) breeding program. All plant samples were obtained from the Spanish almond germplasm collection located at CITA, maintained as living plants grafted on the almond $\times$ peach [Prunus persica (L.) Batsch] hybrid clonal rootstock INRA GF-677 using the standard management practices (Espiau et al., 2002).
DNA EXTRACTION. Genomic DNA was extracted from leaves following the CTAB extraction method based on Doyle and Doyle (1987). For PCR amplification, DNA was diluted to 20 $\mathrm{ng} \cdot \mu \mathrm{L}^{-1}$ in water.

$\boldsymbol{S}$-RNASE ANd SFB ALleles PCR AMPLification. To confirm the identity of the $S$ alleles of these cultivars, the $S$ alleles were amplified according to Tamura et al. (2000), using the primers AS1II and AmyC5R designed for the C1 and C5 conserved regions of almond $S$-RNase alleles. The regions between the signal peptide and the conserved region C5 of the $S_{f}$ allele of 'Cambra' and the putative $S_{f}$ allele of 'Ponç' were amplified according to Ortega et al. (2006) using the forward primer PaConsI-F (Sonneveld et al., 2003) and the reverse primer EM_PC5consRD (Sutherland et al., 2004). PCR reactions were performed in a volume of $30 \mu \mathrm{L}$ containing $1 \times$ PCR buffer (Promega, Madrid, Spain), $1.5 \mathrm{~mm} \mathrm{MgCl}_{2}, 0.2 \mathrm{~mm}$ of each dNTPs, $0.5 \mu \mathrm{M}$ of each primer, one unit of Taq DNA polymerase, and $75 \mathrm{ng}$ of genomic DNA. The PCR program for $S$ RNase allele identification consisted of an initial denaturation of $2 \mathrm{~min}$ at $94^{\circ} \mathrm{C}$, followed by 34 cycles of $1 \mathrm{~min}$ at $95^{\circ} \mathrm{C}, 2 \mathrm{~min}$ at $50{ }^{\circ} \mathrm{C}$, and $4 \mathrm{~min}$ at $72{ }^{\circ} \mathrm{C}$ followed by a final extension of 10 min at $72^{\circ} \mathrm{C}$. A fragment of the SFB locus was PCR-amplified with primers SFB-C1F and SFB-FB3 (Yamane et al., 2003), SFB-C2F (Ikeda et al., 2004), and F-BOX3A' (Vaughan et al., 2006). About $50 \mathrm{ng}$ of genomic DNA was used for PCR amplification in $50 \mu \mathrm{L}$ of reaction mixture containing $1 \times$ PCR buffer, $1.5 \mathrm{~mm}$ of $\mathrm{MgCl}_{2}, 200 \mu \mathrm{M}$ each of dNTPs, $400 \mathrm{~mm}$ of each primer, and one unit of Taq DNA polymerase. For the SFB haplotype amplification, the PCR reactions were run with a program of 35 cycles at $94{ }^{\circ} \mathrm{C}$ for $1 \mathrm{~min}, 54^{\circ} \mathrm{C}$ for $1 \mathrm{~min}$, and 72 ${ }^{\circ} \mathrm{C}$ for $1 \mathrm{~min} 30 \mathrm{~s}$, with initial denaturing at $94{ }^{\circ} \mathrm{C}$ for $3 \mathrm{~min}$ and a final extension of $72^{\circ} \mathrm{C}$ for $10 \mathrm{~min}$.

The PCR products were separated on $1 \%$ agarose gels containing $1 \times$ TAE buffer and were stained with ethidium bromide $\left(0.4 \mu \mathrm{g} \cdot \mathrm{mL}^{-1}\right)$. DNA bands were visualized under ultraviolet light and the images were registered using Gel Doc 2000 (Bio-Rad, Hercules, CA) with Quantity One software (version 4.0.1; Bio-Rad). GeneRuler ${ }^{\mathrm{TM}}$ DNA Ladder Mix (Fermentas, Porto, Portugal) was used as the molecular size standard.

Cloning and gDNA sequencing. For the SFB haplotype, the cloning of the target sequences was done directly from the PCR product after checking the presence of the amplification on agarose gel. For the $S$-alleles, before cloning, the bands corresponding to the target $S$ alleles were purified using the Wizard Plus Miniprep DNA Purification System (Promega) and were quantified on a $1.5 \%$ agarose gel using a standard $1-\mathrm{kb}$ DNA ladder (Invitrogen, Madrid, Spain). The purified PCR products were cloned into the vector pCR2.1 using a TA Cloning Kit (Invitrogen). Insertion was confirmed by restriction enzyme digestion with EcoRI. Plasmids were isolated using the QIA prep Spin Miniprep Kit (Qiagen, Hilden, Germany). For each allele, at least three plasmids from different PCR reactions were sequenced from both ends.

Stylar S-RNaSe analysis. $S$-genotype of 'Ponç' was also determined by separation of stylar RNases linked to SI alleles by NEpHGE as described by Bošković and Tobutt (1996), using as reference the other cultivars included in this study.

Pollination tests. Physiological SI in 'Ponç' and 'Cambra' was studied with three different methods: pollen tube growth, fruit set after artificial hand pollination, and fruit set after bagging. During two consecutives years (2006-07), 50 flowers 
at stage D (Felipe, 1977) were collected from trees growing in the field and taken in plastic bags to the laboratory, emasculated, and placed in trays with tap water. Their pistils were selfor cross-pollinated with 'Marcona' pollen as a control. Pollen was collected and its viability was checked before pollination (Kodad and Socias i Company, 2006). After pollination, trays were kept at room temperature and samples of 10 pistils were collected every $24 \mathrm{~h}$ after pollination, completing $120 \mathrm{~h}$ since pollination. The pistils were autoclaved in a $5 \%$ solution of $\mathrm{Na}_{2} \mathrm{SO}_{3}$ for $12 \mathrm{~min}$ at $1.2 \mathrm{~kg} \cdot \mathrm{cm}^{-2}$. Self- and cross-compatibility was assessed by pollen tube growth after observation in a Leitz Ortholux II microscope (Leitz, Wetzlar, Germany) with ultraviolet illumination of a mercury lamp (Osram HBO 200 W/4; Torrejón de Arsoz, Madrid, Spain) by fluorescence of the callose deposits of the pollen tubes by aniline blue staining after squashing.

Eight branches per cultivar were selected in the field and at least 100 flowers were emasculated per branch and were selfpollinated. In other branches, the flowers were cross-pollinated with 'Marcona' and 'Desmayo Largueta' pollen. Another group of branches were bagged to evaluate the level of self-fertilization of 'Ponç'. Fruit set was recorded in June for all treatments.

\section{Results}

'Ponç' $\boldsymbol{S}$-RNase allele identity. The screening of the $S$ RNase allele diversity in the almond germplasm bank of Zaragoza using allele-specific and conserved primers has allowed the identification of the $S_{f}$ allele in 'Ponç' (Kodad et al., 2008). This allele, using the AS1II and AmyC5R primers, corresponds to a band of size $\approx 1200 \mathrm{bp}$. The deduced amino acid sequence of the $S_{f}$-allele in 'Ponç' is identical to that of the first $S_{f}$ allele (AY291117) amplified in almond from two SC genotypes, 'Lauranne' and Institut de Recerca i Tecnologia Agroalimentària (IRTA) selection 12-2 (Channuntapipat et al., 2001). However, it is only $98 \%$ identical to the $S_{f}$ allele sequenced in 'Tuono' (AF157009) by Ma and Oliveira (2001) and $99.3 \%$ to that by Bošković et al. (2007; AM690356), who gave different sequences for the same allele. The other allele with a band of size $\approx 1700$ bp is identical to $S_{27}$ (AM231675; Ortega et al., 2006).

Using the forward primer PaConsI-F and the reverse primer EM_PC5consRD, a band of 1600 bp was amplified in 'Ponç' and 'Cambra'. The sequencing of this $S_{f}$ showed the typical feature of the Prunus T2-type RNase with five conserved domains (C1, C2, C3, RC4, and C5) and one hypervariable region (Fig. 1). The position of the two introns was also identical to that of other almond $S$-RNases reported by Ortega et al. (2006). The comparison of the sequences as the $S_{f}$ allele of 'Ponç' at the g-DNA and at the deduced amino acid sequence levels showed the same sequence and position of the signal peptide and the first intron of the $S_{f}$ allele identified in 'Cambra', a SC cultivar obtained from the cross of 'Tuono' $x$ 'Ferragnès' (Socias i Company and Felipe, 1999). Thus, the two alleles are identical and no alteration was observed in the primary structure of the encoded almond $S_{f}$-RNase.

The application of NEpHGE in 'Ponç' revealed two different $S$-RNase bands instead of one, as expected in SC genotypes (Bošković et al., 1999), corresponding to $S_{27}$ and $S_{f}$ (Fig. 2). The presence of two bands suggests that the two $S$-RNases of 'Ponç' are functional, including its $S_{f}$-RNase.

SFB IDENTITY IN 'PonÇ'. When the SFB-C1F and SFB-FB3 primers were tested in 'Cambra' $\left(S_{f} S_{3}\right)$ and 'Ferragnès' $\left(S_{1} S_{3}\right)$, DNA sequencing revealed two different kinds of clones; however, just one kind of clone was found in 'Ponç'. The deduced amino acid sequence from the partial genomic DNA of the $\mathrm{SFB}_{1}$ and $\mathrm{SFB}_{3}$ identified in 'Ferragnès', $\mathrm{SFB}_{11}$ and $\mathrm{SFB}_{12}$ in 'Marcona', $\mathrm{SFB}_{3}$ and $\mathrm{SFB}_{\mathrm{f}}$ in 'Cambra', and $\mathrm{SFB}_{\mathrm{f}}$ in 'Ponç' contained a partial sequence of the F-Box motif determined in other SFB S-haplotypes (Ushijima et al., 2003), and two variable regions V1 and V2 (Ikeda et al., 2004).

For 'Ponç' and 'Cambra', the use of SFB-C2F and F$\mathrm{BOX} 3 \mathrm{~A}^{\prime}$ primers allowed the sequencing of the hypervariable regions $\mathrm{HVa}$ and $\mathrm{HVb}$ (Ikeda et al., 2004), located downstream to the V2 region (Fig. 3). The deduced amino acid of the $\mathrm{SFB}_{\mathrm{f}}$ sequence identified in 'Ponç' was identical to that sequenced in 'Tuono' (AM711126; Bošković et al., 2007) and in 'Lauranne' (AB361036; Hanada et al., 2009).

The partial sequences of $\mathrm{SFB}_{3}, \mathrm{SFB}_{12}$, and $\mathrm{SFB}_{\mathrm{f}}$ have been deposited in the database with accession numbers EU293149, EU310402, and EU310402, respectively.

Pollination tests. After confirming the identity of the $S_{f}$ allele RNase and of the SFB $S$-haplotype of 'Ponç' with those of other SC cultivars, pollination tests were conducted to confirm 'Ponç' SC. Pollen viability of 'Ponç' was tested before pollination, showing a high percentage of germination in vitro

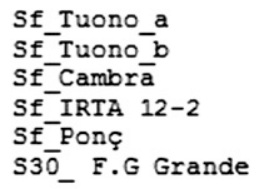

Se Tuono a sf $^{-}$Tuono $b$ Sf_Cambrā Sf_IRTA $12-2$ Sf Ponç S3o_ F.G Grande

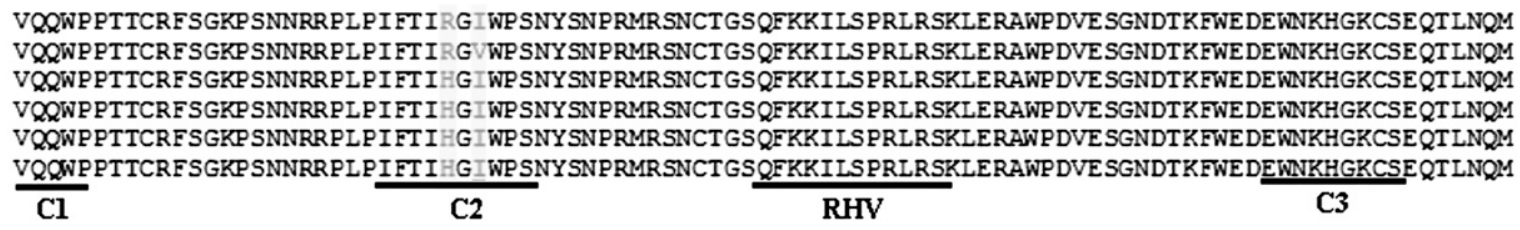

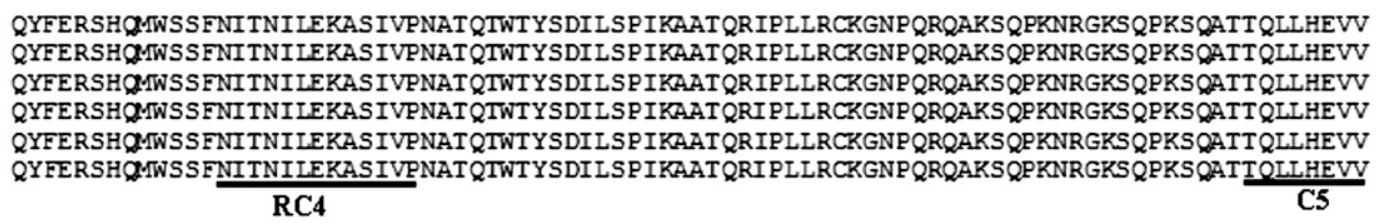

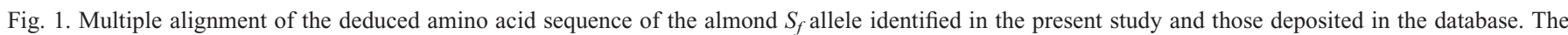
conserved regions (C1-C5) and the hypervariable region (RHV) described in Rosaceae (Ushijima et al., 1998) are boxed. Conserved cysteine and histidine residues are shadowed. European Molecular Biology Laboratory Nucleotide Sequence database (EMBL/GenBank) accession numbers are as follows: $\mathrm{S}_{f}$ of

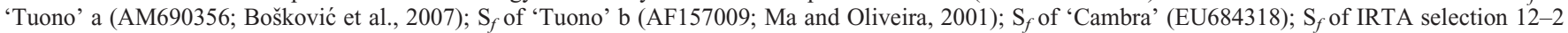
(AY291117; Channuntapipat et al., 2001); S $f a$ of 'Ponç' (EU293146); and $S_{30}$ of 'Fra Giulio Grande' (AM690361; Bošković et al., 2007). 


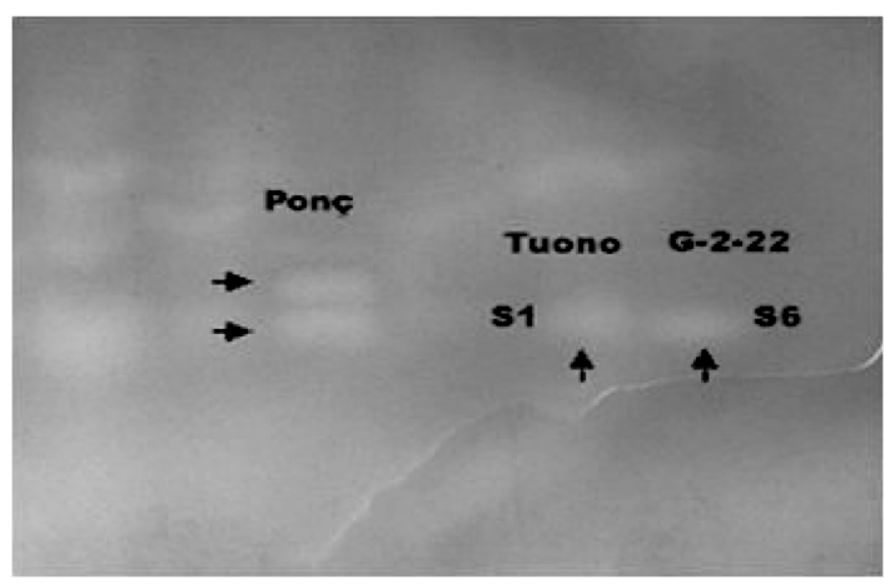

Fig. 2. Zymogram of almond $S$ alleles after NEpHGE showing two bands for 'Ponç' compared to a single band for the self-compatible 'Tuono' and selection G-2-22.

$(\approx 92 \%)$. Pollen germination was also high in self-pollinated pistils in the laboratory, with similar numbers of pollen tubes in the upper third of the style compared with cross-pollinated pistils, with an average of 47 pollen tubes. Pollen tube growth was arrested in the middle third of the style in the selfpollinated pistils, and no pollen tubes were observed at the style base or in the ovary. Conversely, in the cross-pollinated pistils with pollen of 'Marcona' and 'Desmayo Largueta', more than three pollen tubes were observed at the style base. These results were consistent during the 2 years of study. In the field tests, no fruit set was obtained after hand self-pollination, but normal sets, according to the criteria of Kester and Griggs (1959), were obtained after cross-pollination with 'Marcona' and 'Desmayo Largueta' pollen, as well as after selfing 'Cambra' (Table 1). Furthermore, no fruit set was obtained in bagged branches of 'Ponç' during the 2 years of study. The field pollinations by hand or in bagged branches were unaffected by adverse weather conditions in both years, as confirmed by the normal sets in the compatible crosses.

\section{Discussion}

$S$-RNASE AND SFB IDENTITY AND SELF-(IN)COMPATIBILITY EXPRESSION IN 'PoNÇ'. The cloning and sequencing of the $S_{f}$ RNase allele in 'Ponç' (EU310402) showed that it was found to be identical to that of 'Cambra' (EU684318). As well, the deduced amino acid sequence (C1-C5) of the 'Ponç' $S_{f}-$ RNase allele was identical to that determined here in 'Cambra' and to that of 'Lauranne' and the IRTA selection 12-2 (AY291117; Channuntapipat et al., 2001), reported to be derived from selfing 'Lauranne' (Bošković et al., 1999). Hanada et al. (2009) have also identified the partial sequence of the $S_{f}$ RNase allele in 'Lauranne' and found it to be identical to the AY291117 sequence. However, all of these sequences are different from that of 'Tuono' published by Ma and Oliveira (2001; AF157009) or by Bošković et al. (2007; AM690356). The former (AF157009) has valine instead of isoleucine and histidine instead of arginine in the $\mathrm{C} 2$ region (Fig. 1). The latter has histidine instead of arginine (Fig. 1). Taking into account that 'Cambra' and 'Lauranne' are both seedlings from 'Tuono', these cultivars must have inherited the identical $S_{f}-$ RNase allele from 'Tuono', as well as the IRTA selection 12-2 from 'Lauranne'.

Separately, Bošković et al. (2007) have identified in the SI 'Fra Giulio Grande', also from the same Italian region of Apulia as 'Tuono', an $S-$ RNase identical to our $S_{f}-$ RNase of 'Ponç' and 'Cambra' and to $S_{f}-$ RNase of 'Lauranne' and IRTA 12-2 (Channuntapipat et al., 2001). However, Bošković et al. (2007) reported for 'Tuono' a different sequence (AM690356), with a substitution of histidine by arginine in the $\mathrm{C} 2$ region from the consensus $S_{f}$ sequence (Fig. 1). Thus, they suggested a new
SBF30_F.G.Grande SBFE Tuono SBFf Lauranne SBFf_Ponç

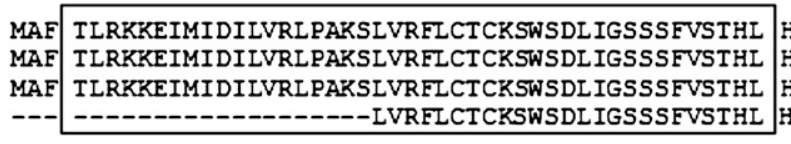

F-box motif

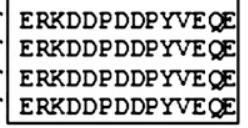

FQWSLFSKETLEE FQWSLFSKETLEE FQWSLFSKETLEE FQWSIFSKETLEE
SBF30_F.G.Grande SBFf Tuono SBFf-Lauranne SBEf_Ponç
CSKLSHPSGSTEHYVIYGSSNGLVCISDE ILNFDSPIHIWNPSVKKFRT PPVSTNINMRFSHVALQFGFHPGVNDYKAVRMMRTNKNALAVEVYSLRT CSKISHPSGSTEHYVIYGSSNGLVCISDE ILNFDSPIHIWNPSVKKFRT PPVSTNINMKFSHVALOFGFHPGVNDYKAVRMMRTNKNAIAVEVYSLRT CSKLSHPSGSTEHYVIYGSSNGLVCISDE ILNFDSP IHIWNPSVKRFRTP PVSTNINMKFSHVALQFGFHPGVNDYKAVRMMRTNKNAIAVEVYSLRT CSKLSHPSGSTEHYVIYGSSNGLVCISDE I LNFDSP IHIWNPSVKRFRT PPVSTNINMKFSHVALQFGFHPGVNDYKAVRMARTNKNAIAVEVYSLRT
SBF30 F.G.Grande SBFf_Tuono SBFf- Lauranne SBEf_Ponç

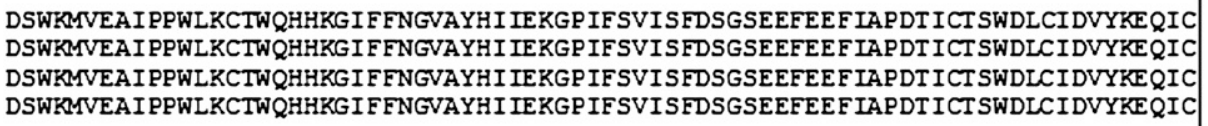

\section{CLLKFYSCEEEDMDKI DLW CLLKFYSCEEEDMDKI DLW CLIKFYSCEEEDMDKT DI CLLKFYSCEEEDMDKI DLW}

V2

SBF30_F.G.Grande SBFf Tuono

SBEf_Lauranne

SBFf_Ponç

\begin{tabular}{|c|c|c|c|}
\hline VLQEKRWKQLCPFV & YPFNYYYGT & IGISIDNKLI & MIKRDDIRGQPDLH \\
\hline VLQEKRWKQLCPFV & YPFNYYYGT & IGISIDNKLI & MLKRDDIRGQPDI \\
\hline VLQEKRWKQLCPEV & YPENYYYGT & IGISIDNKLL & MLKRDDIRGQE \\
\hline VLQEKRWKQLCPFV & YPFNYYYGI & IGISIDNKLI & MLKRDDIRGQPDI \\
\hline
\end{tabular}

LCDYDSKPT QQVLETGIKLATMKYGE IEFLFSLSY LCDYDSKPTQOVLETGIKLATMKYGE IEFLFSLSY LCDYDSKPIQQQVLETGIKLATMKYGE IEFLFSLSY LCDYDSKPTQQVLETGIKLATMKYGE IEFLFSLSY HVa HVb

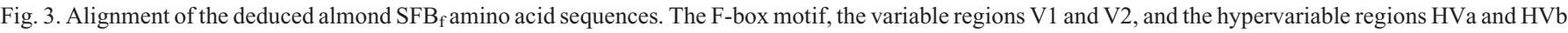
are boxed (Ikeda et al., 2004). European Molecular Biology Laboratory Nucleotide Sequence database (EMBL/GenBank) accession numbers are as follows: SFB30 of 'Fra Giulio Grande' (AM711127; Bošković et al., 2007); SFBf of ‘Tuono' (AM711126; Bošković et al., 2007); SFBf of 'Lauranne’ (AB361036); and SFBf of 'Ponç' (EU310402). 
Table 1. Fruit set after artificial hand-pollination of almond cultivars in the field (100-150 flowers per treatment).

\begin{tabular}{lcccc}
\hline & \multicolumn{4}{c}{ Pollen parent } \\
\cline { 2 - 5 } $\begin{array}{l}\text { Pistil parent } \\
\text { (and } S \text { genotype) }\end{array}$ & Ponç & Cambra & Desmayo Largueta & Marcona \\
\cline { 2 - 5 } $\begin{array}{l}\text { Ponç } \\
\left(S_{f a} S_{27}\right)\end{array}$ & 0 & 25.7 & 28.2 & 19.7 \\
$\begin{array}{l}\text { Cambra } \\
\quad\left(S_{3} S_{f}\right)\end{array}$ & 25.4 & 24.3 & 26.3 & 23.7 \\
$\begin{array}{l}\text { Desmayo } \\
\quad \text { Largueta }\left(S_{I} S_{10}\right)\end{array}$ & 20.2 & 27.3 & 0 & 23.5 \\
$\begin{array}{l}\text { Marcona } \\
\left(S_{11} S_{12}\right)\end{array}$ & 29.7 & 33.1 & 32.2 & 0 \\
\hline
\end{tabular}

allele, $S_{30}$, (AM690361) present in 'Fra Giulio Grande', but not differing from the consensus $S_{f}$ sequence, concluding that this $S_{30}$ is the wild-type allele from which $S_{f}$ was a stylar mutation called $S_{30}{ }^{\circ}$ conferring $\mathrm{SC}$ in almond. This terminology is confusing because they attribute a new number $\left(S_{30}\right)$ for an existing allele $\left(S_{f}\right)$ and establish a new allele $\left(S_{30}{ }^{\circ}\right)$ as a result of a possible missequencing. Consequently, the $S_{30}$-RNase allele identified by Bošković et al. (2007) and the $S_{f}$-RNase allele of 'Ponç' correspond to the $S_{f}$-RNase allele already sequenced in $\mathrm{SC}$ almond cultivars and selections (Channuntapipat et al., 2001).

The pollination tests showed that 'Ponç' is physiologically SI. However, although the growth of the self-pollen was arrested in 'Ponç' pistils, the good growth of a cross-compatible pollen showed that these pistils are able to sustain the tube growth of foreign pollen. In addition, the good germination of 'Ponç' pollen indicates its high viability, as well as the fruit set of 'Marcona' after hand pollination by 'Ponç' pollen. There were no available cultivars sharing the same $S$ genotype as 'Ponç', therefore the functionality and ability of the pollen harboring the same $S$-genotype than 'Ponç' in reaching the style base could not be tested.

The ribonuclease activity of the $S$-RNases is shown to be essential for the SI reaction (Huang et al., 1994; Sassa et al., 1997). In almond, SC has been associated with the absence of a stylar RNase band (Bošković et al., 1999), as well as in japanese pear (Pyrus serotina Rehd.) (Sassa et al., 1992). The fact that RNase activity is required for the function of the $S$-RNases, and that $S$-RNases are taken up by self- and nonself-pollen tubes, suggests that the $S_{f}$-RNase of 'Ponç' is functional and degrades the RNA of self-pollen. Bošković et al. (2007) have also identified three Italian SI almond cultivars, 'Cinquanta Vignali', 'Fra Giulio Grande', and 'Santoro', with the $S$-RNase allele identical to that found in 'Ponç' that showed ribonuclease activity. The ribonuclease activity of the $S_{f}$-RNase allele of 'Ponç' explains the results of pollen tube growth and fruit set when 'Ponç' was self-pollinated.

$\mathrm{SC}$ in 'Cambra', IRTA 12-2, and 'Lauranne' could be the result of a mutation or alteration in the coding region of the $S_{f^{-}}$ RNase gene, as mentioned in other species. In Lycopersicon peruvianum (L.) Mill., some spontaneous SC accessions have an amino acid substitution at one of the essential histidines in the catalytic domain of the $S$-RNase that leads to a complete loss of enzymatic activity (Kowyama et al., 1994; Royo et al., 1994). In Petunia inflata R. Fries, the mutant $S_{3}$ allele mutagenized by replacing the codon for His-93 with a codon for aspargine, producing a mutant protein that does not exhibit any detectable ribonuclease activity (Huang et al., 1994). However, in the present study, no mutation of histidine to other amino acids was detected in the $S_{f}$ allele in SC almond cultivars.

Recently, Tao et al. (2007) reported an inactive $S_{2 m}$-RNase in several cultivars of peach and attributed the reduction of RNase stability to the replacement of a structurally important cysteine residue in the $\mathrm{C} 5$ region by tyrosine. In the present study, we have not completely sequenced the $S_{f}$-RNase clone, but the complete deduced amino acid sequence of $S_{f}$-RNase of IRTA selection 12-2 (AY291117) contains a cysteine residue.

The SC observed in some cultivars of several Prunus species has been reported to be due to a defective function of the pollen, as a result of a mutation, deletion, or insertion in the coding region of the SFB $S$-haplotype, such as in $P$. avium and $P$. mume Sieb. et Zucc. (Ushijima et al., 2004), P. armeniaca L. (Vilanova et al., 2006), and P. persica (Tao et al., 2007). However, the identity of the partial sequence of 'Ponç' $\mathrm{SFB}_{\mathrm{f}}$ and that of 'Lauranne' (AB361036; Hanada et al., 2009) and 'Tuono' (AM711126; Bošković et al., 2007) indicates that there is no alteration in any of the two components of the $S_{f}$ allele in 'Ponç', either in the pistil or the pollen parts. Moreover, the identity of $\mathrm{SFB}_{\mathrm{f}}$ from 'Lauranne' and 'Tuono', and of $\mathrm{SFB}_{30}$ (AM711127) from 'Fra Giulio Grande', a SI Italian cultivar (Bošković et al., 2007), indicates that the origin of SC in almond is not related to any alteration or mutation in the SFB gene in almond.

These results confirm that 'Ponç' and 'Cambra' in the present study, as well as 'Lauranne' (Hanada et al., 2009), share the same $\mathrm{SFB}_{\mathrm{f}}$ allele but present a different phenotypic expression. As far as we know, this is the first time that an almond cultivar has been identified as possessing the $S_{f}$ allele, associated with SC expression, but being phenotypically SI. Alonso and Socias i Company (2005) reported that some inbred SC genotypes, having 'Tuono' as a donor for the SC trait, in spite of the presence of the $S_{f}$ allele, showed a SI phenotype, indicated by a very low number of pollen tubes at the base of low number of pistils. However, this was the result of the inbreeding depression observed in that population, whereas in the present work, all self-pollinated pistils showed the arrest of the pollen tubes in the middle part of the style, which is a different phenomenon. This $S_{f}$ allele, showing ribonuclease activity and being expressed in 'Ponç', may be called $S_{f a}$ (active $S_{f}$-allele).

Hypothesis ON THE ORIGIN OF SELF-COMPATIBILITY IN ALMOND. It has been suggested that $\mathrm{SC}$ in almond could be explained by quantifying the transcript expression of the $S$ RNases in the style. Watari et al. (2007) reported that the low transcriptional level of the $\mathrm{Se}$-RNase resulted in an insufficient $\mathrm{Se}$-RNase accumulation in the pistils, thus conferring $\mathrm{SC}$ in japanese plum (Prunus salicina Lindl.). Qin et al. (2006) have estimated the threshold amount of $S_{12}$-RNase required for pollen rejection in Solanum chacoesense Bitt. and reported that an insufficient accumulation confers SC. In almond, SC has already been attributed to the lack of ribonuclease activity of the $S_{f}$ allele in the pistil (Bošković et al., 1999). However, it is not known thus far whether the change affecting $S_{f}$-RNase expression in almond is at the transcriptional or translational level.

The absence of any alteration in the coding region of the $S_{f^{-}}$ allele in the SI and SC cultivars indicates that the appearance of $\mathrm{SC}$ in almond could be due to a change outside the coding region or to the presence of a modifier gene. Yamane et al. 
(2003) reported that the inactivation of the $S_{6 m}$-RNase in Prunus cerasus L. is due to an insert of 2600 bp located upstream of the $S$-RNase coding sequence. Further analysis should be undertaken to ascertain if there is any insertion in the $S_{f}$ allele from SC and SI almond cultivars that could explain the inactivation of the $S_{f}$ allele in SC almond cultivars. In Prunus pseudocerasus Lindl., it has been suggested that SC could be caused by mutations in other genes critical for the SI reaction (Huang et al., 2008).

In conclusion, we have isolated and sequenced, for the first time, the coding sequence for $S_{f}-$ RNase and partial $\mathrm{SFB}_{\mathrm{f}}$ from two cultivars originated from two different geographic regions and showing a different phenotypic expression. The present results show that the coding region of the $S_{f}$ gene may not be the exclusive origin of SC in almond. Further experiments involving the complete sequence of the $S_{f}$-RNase gene in SC and SI cultivars to confirm its identity and the expression analysis of the $S_{f a}$-RNase in 'Ponç' is required to determine the characteristics of the transcribed proteins of the expressed $S_{f a}$ allele in almond.

\section{Literature Cited}

Alonso, J.M. and R. Socias i Company. 2005. Self-compatibility expression in self-compatible almond genotypes may be due to inbreeding. J. Amer. Soc. Hort. Sci. 130:868-869.

Alonso, J.M. and R. Socias i Company. 2007. Negative inbreeding effects in tree fruit breeding: Self-compatibility transmission in almond. Theor. Appl. Genet. 115:151-158.

Bošković, R. and K.R. Tobutt. 1996. Correlation of stylar ribonuclease zymograms with incompatibility alleles in sweet cherry. Euphytica 90:245-250.

Bošković, R., K.R. Tobutt, E. Ortega, B.C. Sutherland, and A. Godini. 2007. Self-(in)compatibility of the almond $P$. dulcis and $P$. webbii: Detection and cloning of 'wild-type $S_{f}$ ' and new self-compatibility alleles encoding inactive $S$-RNases. Mol. Genet. Genomics 278:665676.

Bošković, R., K.R. Tobutt, H. Duval, I. Batlle, F. Dicenta, and J.F. Vargas. 1999. A stylar ribonucleases assay to detect self-compatible seedlings in almond progenies. Theor. Appl. Genet. 99:800-810.

Bošković, R., K.R. Tobutt, I. Batlle, H. Duval, P. Martínez-Gómez, and T.M. Gradziel. 2003. Stylar ribonuclease in almond: Correlation with and prediction of incompatibility genotypes. Plant Breed. 122:70-76.

Channuntapipat, C., M. Sedgley, and G. Collins. 2001. Sequences of cDNAs and genomic DNAs encoding the $S_{1}, S_{7}, S_{8}$ and $S_{f}$ alleles from almond, Prunus dulcis. Theor. Appl. Genet. 103:1115-1122.

Crane, M.B. and W.J.C. Lawrence. 1929. Genetical and cytological aspects of incompatibility and sterility in cultivated fruits. J. Pomol. Hort. Sci. 7:276-301.

Crossa-Raynaud, P. and C. Grasselly. 1985. Éxistence de groupes d'interstérilite chez l'amandier. Options Méditerranéennes CIHEAM/IAMZ 85(1):43-45.

Doyle, J.J. and J.L. Doyle. 1987. A rapid DNA isolation procedure for small quantities of fresh tissue. Phytochem. Bul. 19:11-15.

Entani, T., M. Iwano, H. Shiba, F.S. Che, A. Isogai, and S. Takayama. 2003. Comparative analysis of the self-incompatibility $(S$-) locus region of Prunus mume: Identification of a pollen-expressed F-box gene with allelic diversity. Genes Cells 8:203-213.

Espiau, M.T., J.M. Ansón, and R. Socias i Company. 2002. The almond germplasm bank of Zaragoza. Acta Hort. 591:275-278.

Felipe, A.J. 1977. Almendro. Estados fenológicos. Información Técnica Económica Agraria 27:8-9.

Hanada, T., K. Fukuta, H. Yamane, R. Tao, J.M. Alonso, and R. Socias i Company. 2009. Cloning of self-compatible $S^{f}$ locus in almond. Acta Hort. (in press).
Huang, S., H.S. Lee, B. Karunanandaa, and T.H. Kao. 1994. Ribonuclease activity of Petunia inflata $S$ proteins is essential for rejection of self-pollen. Plant Cell 6:1021-1028.

Huang, S.X., H.Q. Wu, Y.R. Li, J. Wu, S.J. Zhang, W. Heng, and S.L. Zhang. 2008. Competitive interaction between two functional $S$ haplotypes confer self-compatibility on tetraploid Chinese cherry (Prunus pseudocerasus Lindl. cv. Nanjing Chuisi). Plant Cell Rep. 27:1075-1085.

Ikeda, K., B. Igic, K. Ushijima, H. Yamane, N.R. Hauck, R. Nakano, H. Sassa, A.F. Iezzoni, J.R. Kohn, and R. Tao. 2004. Primary structural features of the $S$ haplotype-specific F-box protein, SFB, in Prunus. Sex. Plant Reprod. 16:235-243.

Ikeda, K., K. Ushijima, H. Yamane, R. Tao, N.R. Hauck, A.M. Sebolt, and A.F. Iezzoni. 2005. Linkage and physical distances between the $S$-haplotype $S$-RNase and $S F B$ genes in sweet cherry. Sex. Plant Reprod. 17:289-296.

Kao, T.-H. and T. Tsukamato. 2004. The molecular and genetic bases of $S$-RNase-based self-incompatibility. Plant Cell 16:72-83.

Kester, D.E. and W.H. Griggs. 1959. Fruit setting in the almond: The effect of cross-pollinating various percentages of flowers. Proc. Amer. Soc. Hort. Sci. 74:214-219.

Kodad, O. and R. Socias i Company. 2006. Pollen source effect on pollen tube growth in advanced self-compatible almond selections (Prunus amygdalus Batsch). Adv. Hort. Sci. 20:256-261.

Kodad, O. and R. Socias i Company. 2008. Fruit set evaluation for selfcompatibility selection in almond. Scientia Hort. 118:260-265.

Kodad, O., J.M. Alonso, A. Sánchez, M.M. Oliveira, and R. Socias i Company. 2008. Evaluation of genetic diversity of $S$-alleles in an almond germplasm collection. J. Hort. Sci. Biotechnol. 83:603-608. Kowyama, Y., C. Kunz, I. Lewis, E. Newbigin, A.E. Clarke, and M.A. Anderson. 1994. Self-compatibility in a Lycopersicon peruvianum variant (LA2157) is associated with a lack of style $S$-RNase activity. Theor. Appl. Genet. 88:859-864.

Ma, R.C. and M.M. Oliveira. 2001. Molecular cloning of the selfincompatibility genes $S_{1}$ and $S_{3}$ from almond (Prunus dulcis) cv. Ferragnès. Sex. Plant Reprod. 14:163-167.

McClure, B.A., V. Haring, P.R. Ebert, M.A. Anderson, R.J. Simpson, F. Sakiyama, and A.E. Clarke. 1989. Style self-incompatibility gene products of Nicotiana alata are ribonucleases. Nature 342:955-957.

Ortega, E., R. Bošković, D.J. Sargent, and K.R. Tobutt. 2006. Analysis of $S$-RNase alleles of almond (Prunus dulcis): Characterization of new sequences, resolution of synonyms and evidence of intragenic recombination. Mol. Genet. Genomics 276:413-426.

Qin, X., B. Liu, J. Soulard, D. Morse, and M. Cappadocia. 2006. Style by style analysis of two sporadic self-compatible Solanum chacoense lines supports a primary role for $S$-RNase in determining pollen rejection thresholds. J. Expt. Bot. 57:2001-2013.

Royo, J., C. Kunz, Y. Kowyama, M. Anderson, A.E. Clarke, and E. Newbigin. 1994. Loss of a histidine residue at the active site of $S$ locus ribonuclease is associated with self-compatibility in Lycopersicon peruvianum. Proc. Natl. Acad. Sci. USA 91:6511-6514.

Rubí V. 1980. El almendro. Delegación de Baleares, Ministerio de Agricultura, Palma de Mallorca, Spain.

Sassa, H., H. Hirano, and H. Ikehashi. 1992. Self-incompatibilityrelated RNases in styles of japanese pear (Pyrus serotina Rehd.). Plant Cell Physiol. 33:811-814.

Sassa, H., H. Hirano, T. Nishio, and T. Koba. 1997. Style-specific selfincompatibility mutation caused by deletion of the $S$-RNase gene in japanese pear (Pyrus serotina). Plant J. 12:223-227.

Socias i Company, R. 1984. Genetic approach to the transmission of self-compatibility in almond (Prunus amygdalus Batsch). Options Méditerranéennes CIHEAM/IAMZ 84(1):123-127.

Socias i Company, R. 1990. Breeding self-compatible almonds. Plant Breed. Rev. 8:313-318.

Socias i Company, R. 2002. Latest advances in almond self-compatibility. Acta Hort. 591:205-212.

Socias i Company, R. 2004. The contribution of Prunus webbii to almond evolution. Plant Genet. Resour. Newsl. 14:9-13. 
Socias i Company, R. and A.J. Felipe. 1999. 'Blanquerna', 'Cambra', y 'Felisia': Tres nuevos cultivares autógamos de almendro. Información Técnica Económica Agraria 95(5):111-117.

Socias i Company, R., D.E. Kester, and M.V. Bradley. 1976. Effects of temperature and genotype on pollen tube growth of some selfcompatible and self-incompatible almond cultivars. J. Amer. Soc. Hort. Sci. 101:490-493.

Sonneveld, T., K.R. Tobutt, and T.P. Robbins. 2003. Allele-specific PCR detection of sweet cherry self-incompatibility $(S)$ alleles $S_{I}$ to $S_{16}$ using consensus and allele-specific primers. Theor. Appl. Genet. 107:1059-1070.

Sutherland, B.G., T.P. Robbins, and K.R. Tobutt. 2004. Primers amplifying a range of Prunus S-alleles. Plant Breed. 123:582-584.

Tamura, M., K. Ushijima, H. Sassa, H. Hirano, R. Tao, T.M. Gradziel, and A.M. Dandekar. 2000. Identification of self-incompatibility genotype of almond by allele-specific PCR analysis. Theor. Appl. Genet. 101:344-349.

Tao, R., A. Watari, T. Hanada, T. Habu, H. Yaegaki, M. Yamaguchi, and H. Yamane. 2007. Self-compatible peach (Prunus persica) has mutant versions of the $S$ haplotypes found in self-incompatible Prunus species. Plant Mol. Biol. 63:109-123.

Ushijima, K., H. Sassa, A.M. Dandekar, T.M. Gradziel, R. Tao, and H. Hirano. 2003. Structural and transcriptional analysis of the self- incompatibility locus of almond: Identification of a pollen-expressed F-Box gene with haplotype-specific polymorphism. Plant Cell 15:771-781.

Ushijima, K., Y. Yamane, A. Watari, E. Kakehi, K. Ikeda, R.H. Huak, A.F. Iezzoni, and R. Tao. 2004. The $S$-haplotype-specific F-Box protein gene, SFB, is defective in self-compatible haplotypes of Prunus avium and P. mume. Plant J. 39:573-586.

Vaughan, S.P., K. Russell, D.J. Sargent, and K.R. Tobutt. 2006. Isolation of $S$-locus F-box alleles in Prunus avium and their application in a novel method to determine self-incompatibility genotypes. Theor. Appl. Genet. 112:856-866.

Vilanova, S., M.L. Badenes, L. Burgos, J. Martínez-Calvo, G. Llácer, and C. Romero. 2006. Self-compatibility of two apricot selections is associated with two pollen part mutations of different nature. Plant Physiol. 142:629-641.

Watari, A., T. Hanada, H. Yamane, T. Esumi, R. Tao, H. Yaegaki, M. Yamaguchi, B. Beppu, and I. Kataoka. 2007. A low transcriptional level of $S^{e}$-RNase in the $S^{e}$-haplotype confers self-compatibility in japanese plum. J. Amer. Soc. Hort. Sci. 132:396-406.

Yamane, H., K. Ikeda, N.R. Hauck, A.F. Iezzoni, and R. Tao. 2003. Self-incompatibility $(S)$ locus region of the mutated $S_{6}$-haplotype of sour cherry (Prunus cerasus) contains a functional pollen $S$ allele and non-functional pistil allele. J. Expt. Bot. 54:2431-2437. 